\title{
Curriculum Reform of Computer Programming and Computational Thinking Training
}

\author{
Ying Liu ${ }^{1, \mathrm{a}}$, Zhipeng $\mathrm{Hu}^{2, \mathrm{~b}}$ * \\ ${ }^{1}$ Information Technology and Media College of Beihua University, Jilin 132013, China \\ ${ }^{2}$ Information Technology and Media College of Beihua University, Jilin 132013, China \\ am18604496851@163.com, ${ }^{b}$ huzhipengstudy@163.com
}

Keywords: Computational thinking; Computer programming course

\begin{abstract}
The cultivation of computational thinking ability is an important part of general education in universities. At present, there are some problems in the teaching of computer programming course in Colleges and universities. These problems form obstacles to the cultivation of students' Computational Thinking ability. Through the analysis of computational thinking, from the aspects of re organizes teaching content, strengthen teaching reform and enrich the second classroom for students of reform and practice of computer programming course based on computational thinking.
\end{abstract}

\section{Introduction}

Computational thinking is an important topic in the teaching research of computer basic education in universities, and it is also an important concept which is widely concerned by the international computer community. Department of computer science professor Zhou Yizhen director of the United States in March 2006 at Carnegie Mellon made the following definition of Computational Thinking in the United States computer authoritative journals Communications of the ACM: computational thinking refers to the use of the fundamental concept of computer science, problem solving, system design and human behavior understanding covers a series of computer science, thinking [1].

In July 2010, the first seminar on the nine school Consortium (C9) computer basic course was held in Xi'an Jiao Tong University". Experts at the university computer foundation teaching the same consensus, the core task of college computer based teaching is to cultivate the computational thinking ability of students, and thus the construction of computer basic course system and teaching content is more complete. In November 2010, Shandong University hosted the sixth university computer courses forum ", University of Science \&amp; Technology China academician Guoliang Chen proposed computational thinking into the university computer foundation teaching, and gives the minimum set of teaching with computational thinking as the core of the basic computer course in University, which indicates the reference direction of reform of computer basic education in university. November 2010 Shandong University academician Guoliang Chen visit everyone pulpit, talked about the calculation of the basic computer education thinking and college; University of Science and Technology of China in March 2012 held a "teaching communication design and Computational Thinking" program of seminars; HeFei University of Technology in May 2012 is College of computer and information invited national teaching Masters academician Guoliang Chen entitled "Computational Thinking: university education, the revitalization of science and engineering calculation study on the innovation"; May 2012 Huazhong University of Science and Technology held a "high school" Computational Thinking and basic computer "teaching seminar" in July 2012; Beijing Jiaotong University And Information Technology Institute held a university computer foundation course construction and teaching exchange meeting based on computational thinking. The National Institutes of higher learning discuss the teaching reform of university computer basic courses with the core of Computational Thinking ability. 


\section{The Current Situation of Programming Course}

In most colleges and universities, computer programming course is not only a compulsory course and an introductory course for students majoring in computer science, but also a required course and basic course for non computer majors. According to the relevant investigation and data, in recent years there has been a contradiction between the demand for computer talents. On the one hand, the social demand for talents of software development, computer professional talent gap is large, on the other hand it is a computer and related professional low employment rate of graduates can not find the ideal job; non computer professional students while learning $\mathrm{C}$ program design, $\mathrm{VB}$ program design course, but a lot of students in solving problems not, using the computer as an indispensable tool for thinking and expression, have not yet established a calculation mode of thinking of program design, will not use the computer consciousness to think about the problem, not the application of computer technology to solve professional problems [2].

Computer program design curriculum teaching at present has many drawbacks, the performance of teaching methods of teachers and students to compare the mechanical curing, subordinate passive; teaching content is limited to the professor echo what the books say, a popular computer language and not in the teaching to reveal the various computer programming language in common, students cannot understand overview of other languages through a computer language; teaching skills in English grammar in detail and ignore the demand analysis, function, programming and algorithm design, resulting in students' programming confusion, lack of clarity, the code is not standardized, procedures for poor readability.

In the program design course teaching, teachers focus on process sentences, grammar rules and some of the details of the talks, while ignoring cultivate algorithm thinking and problem solving methods and skills, so it is difficult to mobilize the students' enthusiasm and initiative in program design, and can not develop logical thinking ability, abstract generalization ability, training students' problems analyzing and solving ability [3]. By the teaching plan of the limited time, the focus of teaching program design course is not to teach the students how to solve some practical problems, but the cultivation of students' comprehensive consideration and analysis of the mode of thinking, improve the students thinking ability of practice, to promote students' active learning and exploring consciousness, enhance students' creative ability and comprehensive quality [4].

The process of teaching in programming courses, the focus of the examination is still based on the theory of knowledge, examination content focuses on some basic concepts, details of grammar and grammar rules, examination forms or traditional single final examination, not flexible. Students' learning initiative, Exam Cram cram, which is not conducive to fully and accurately check the quality of student learning, is not conducive to the basic computer teaching to cultivate the ability of Computational Thinking as the core task [5]. The examination of the programming course should focus on examining the thinking mode and the basic method of the program design of the students using computer to solve the problem, rather than the programming language itself. In addition, the examination form can be diversified, emphasizing the practical assessment, comprehensive and flexible and reasonable use of the closed book, open book, site programming problems and questions, questioning and answering a variety of assessment methods, improve the students' learning initiative, stimulate students' interest in learning.

\section{Teaching Reform and Exploration Practice of Programming Course}

The teaching content of program design course includes three aspects: program design language, algorithm description and programming debugging. Algorithm description is the accurate and complete description of the problem solving method, which belongs to the category of computational thinking, while programming language and programming debugging are not the content of computational thinking. Programming course is a typical computational thinking course [6]. The curriculum goal of university computer programming is to enable students to consciously learn and introduce some concepts, techniques and methods in Computer Science in their respective majors...... Using computer to recognize and deal with the possible problems in computer 
applications". In short, it is the use of computer science and technology and methods to deal with problems, which is the goal of computational thinking.

The program design course content is an important content of the computational thinking ability, teachers should take the solving process and method of solving practical problems for the guidance of teaching, the basic method of programming, will integrate knowledge in programming language syntax to program design, to avoid the boring grammar description. For most of the non computer professional students, learning programming is not intended to be a programmer, but to master the basic programming ideas and methods, learn to analyze and solve the problems of the basic idea and the process of using the computer program, the development of logical thinking ability and improve reasoning ability and lay a good foundation for learning professional courses. We need to cultivate the computational thinking ability as the core task, re organization and re combing of the existing program design course teaching goal and the teaching reform of the curriculum system structure, design procedures, improve teaching methods, highlighting the cultivation of Computational Thinking ability [7]. At the same time, the program design course teaching without involving all aspects of computational thinking, which is different from the computer teaching, should be oriented to the application needs of professional computer, cultivate students' Computational Thinking to solve the professional problems of thinking and skills.

Teachers can set up online FAQ question answering system, convenient for students and teachers responsum; can set up their own website, carry out network teaching work; constantly update and improve the online teaching resources, combining with the teaching practice, play a greater role in the process of teaching. Teachers should carefully design high quality electronic teaching plans and teaching cases, write teaching courseware with pictures and illustrations, make full use of multimedia teaching equipment, improve students' interest in learning and classroom teaching effect. Teachers should study on the assessment methods of program design course, improve and perfect the curriculum evaluation mode of the existing examination system reform and form a single, the use of scientific, reasonable and comprehensive evaluation methods.

In the process of teaching, teachers should strengthen the cultivation of students' computational thinking ability, make it clear that program design is only a means to achieve computational thinking. Classroom teachers should pay attention to the cultivation of students' computational thinking ability, according to the individual differences of students, to promote students' computational thinking ability, let students create new things in thinking. Teachers should improve Tangguan or cramming the traditional teaching method and the teaching idea, thinking to students autonomy, let the students from the class notes, notes, exam exam back after liberation of all forget the examination exam, keep up with the teacher teaching idea, let students personalized active learning, give full play to the main role of students in teaching. Due to limited teaching hours, teachers should more effectively organize the teaching in the teaching process, should be in order to explain the algorithm method and construction process, let students grasp the programming methods, to cultivate students' correct mode of thinking, without too much emphasis on grammar and implementation details of algorithm, more time left to the students thinking and discussion, to the students a free play of imagination and creativity in space.

To cultivate the computational thinking ability of students, in addition to the lectures focus on speaking thinking, problem analysis and abstraction of the problem domain, but also the choice of Computing Subject in some interesting and attractive examples to guide students to read and think of ideas and methods, which solve the problem of open thinking, inspiration. Starting with the algorithm, the project case teaching method formed by task driven and computer practice has a good effect on the cultivation of students' Computational Thinking and the improvement of programming interest. In teaching, teachers can use the following three principles: (1) Programming language grammar rules, teachers can organize some project case to explain the knowledge points through the project case, so the students can apply their knowledge to fully mobilize students' interest in learning, arouse the curiosity of students, improve students' learning enthusiasm. This is conducive to the cultivation of students' Computational Thinking Ability and self-learning ability, and avoid students' learning interest due to the boring and complicated grammar rules of the 
program language. (2) Project oriented, task driven, organization and implementation of program design teaching. Taking the project as the main line, led by the teacher, to the student, the teaching content of task, task driven teaching, can increase students' learning pressure and learning motivation, stimulate students' autonomous learning, positive thinking. (3) Pay attention to the practical teaching link, realize the organic combination of theory teaching and practice teaching. The classroom teaching, teaching materials, experimental guidance and practice, network courses and other resources combined, always grasp the practice, cultivate the students' computational thinking ability, strengthen the students' learning method guidance. Students continue to debug the program, and constantly modify the process, and further strengthen and train the students' programming thinking mode of calculation. Through the practice of computer, students can really feel, understand and understand the thought, method and thinking mode of programming problem solving.

Computational thinking, focusing on the training of professional talents, carries out effective guidance and careful organization of students' second classroom life, and closely integrates students' second classroom life with professional learning. Most of the program design course is offered in the university the first grade, the teacher can focus on program design on students' extracurricular activities in this period to carry out rich and colorful activities, create a learning program design team, and actively organize students design competition and strengthen students' science and technology innovation direction of the competition, this is an important way to cultivate students' Computational Thinking the ability of the training of college students consciousness of teamwork, leadership and coordination ability, communication skills, learning ability and innovation ability and comprehensive quality and professional occupation ability also plays an important role in.

\section{Conclusion}

Computational thinking is also closely related to our lives, from biological theory to mapping science, from defense industry to space technology, each profession is associated with computational thinking. Training students' computational thinking ability will greatly improve students' cognitive ability and lay a good foundation for their professional learning. At present, some colleges and universities in China has started the practice exploration of Computational Thinking of computer based curriculum reform, such as Shanghai Jiao Tong University, Xi'an Jiao Tong University, Shenzhen University, South University of science and technology, Harbin Institute of Technology. The computer course teaching reform with computational thinking as the core is a complex system engineering, which requires us to continue to learn, study, practice, summarize and optimize, and have a long way to go.

\section{Acknowledgments}

This work is supported by the Teaching Research Project of the College of Beihua University of Jilin Province (No. XJQN2017040)

\section{References}

[1] Eri Nakatani-Webster,Abhinav Nath. Inferring Mechanistic Parameters from Amyloid Formation Kinetics by Approximate Bayesian Computation [J]. Biophysical Journal,2017,:.

[2] Hatice Yildiz Durak,Mustafa Saritepeci. Analysis of the relation between computational thinking skills and various variables with the structural equation model [J]. Computers \&amp; Education, 2017,:

[3] Ibrahim Cetin,Ed Dubinsky. Reflective Abstraction in Computational Thinking [J]. Journal of Mathematical Behavior,2017,:

[4] Marcos Román-González,Juan-Carlos Pérez-González,Carmen Jiménez-Fernández. Which cognitive abilities underlie computational thinking? Criterion validity of the Computational Thinking Test $[\mathrm{J}]$. Computers in Human Behavior,2016,: 
[5] Marcos Román-González,Juan-Carlos Pérez-González,Jesús Moreno-León,Gregorio Robles. Extending the nomological network of computational thinking with non-cognitive factors [J]. Computers in Human Behavior,2017,:

[6] Maria José Marcelino,Teresa Pessoa,Celeste Vieira,Tatiana Salvador,António José Mendes. Learning Computational Thinking and scratch at distance[J]. Computers in Human Behavior,2017,:

[7] Soumela Atmatzidou,Stavros Demetriadis. Advancing students' computational thinking skills through educational robotics: A study on age and gender relevant differences [J]. Robotics and Autonomous Systems, 2016,75: 